\title{
Queixa escolar: repercussões na escola a partir do atendimento psicológico
}

\author{
Vanessa Milani Labadessa \\ Instituto Federal de Educação Ciência e Tecnologia de Rondônia - Ariquemes - RO - Brasil \\ Vanessa Aparecida Alves de Lima \\ Universidade Federal de Santa Catarina - Joinville - SC - Brasil
}

\begin{abstract}
Resumo
Para além das dificuldades culturais ou estruturais que as escolas tenham para discutir a queixa escolar como uma produção da inter-relação de seus atores no campo sóciopolítico, partimos das alegações das próprias escolas para compreender como essas instituições se reorganizam a partir das devolutivas de atendimento de alunos encaminhados, com queixa escolar, para atendimento psicológico. Pesquisamos nove escolas públicas municipais em Ariquemes (RO), realizamos análise documental dos encaminhamentos e entrevistamos as Orientadoras Educacionais das instituições e a Psicóloga que faz os atendimentos encaminhados num núcleo de saúde do município. Os resultados apontam para a ausência de registros adequados e de modificações na organização das instituições analisadas a partir dos retornos dos atendimentos psicológicos, uma vez que a escola não cria espaços para a discussão sobre a queixa escolar, perpetuando assim a culpabilização somente do aluno e sua família pela queixa escolar.
\end{abstract}

Palavras-chave: Queixa escolar; Educação; Orientação Educacional.

\section{School complaint: repercussions at school from psychological support}

\begin{abstract}
In addition to the cultural or structural difficulties that schools have in discussing school complaints as a production of their actors' interactions in the socio-political field, we started from the schools' own claims to understand how these institutions reorganize themselves from the students' sent to school with psychological complaints. We researched 09 municipal public schools in Ariquemes (RO), carried out documentary analysis of the referrals and interviewed the Educational Advisors of the institutions and the Psychologist who does the referred calls in a health center of the municipality. The results point to the absence of adequate records and the absence of modifications in the organization of the analyzed institutions, based on the psychological care returns, since the school does not create spaces for the discussion about the school complaint, thus perpetuating the blame only of the student and his family for the school complaint.
\end{abstract}

Keywords: School Complaints; Education; Educational Guidance.

\section{Queja escolar: repercusiones en la escuela a partir de la atención psicológica}

\section{Resumen}

Para más allá de las dificultades culturales o estructurales que las escuelas tengan para discutir la queja escolar como una producción de la interrelación de sus actores en el campo socio político, partimos de las alegaciones de las propias escuelas para comprender como estas instituciones se reorganizan a partir de las devolutivas de atención de alumnos encaminados, con queja escolar, para atención psicológica. Se investigó 09 escuelas públicas municipales en Ariquemes (RO), se realizó análisis documental de los encaminamientos y se entrevistaron las Orientadoras Educacionales de las instituciones y la Psicóloga que hace los atendimientos encaminados en un núcleo de salud del municipio. Los resultados apuntan para ausencia de registros adecuados y ausencia de modificaciones en la organización de las instituciones analizadas a partir de los retornos de los atendimientos psicológicos, una vez que la escuela no ofrece espacios para la discusión sobre la queja escolar, perpetuando así la culpabilidad solamente del alumno y su familia por la queja escolar.

Palabras clave: Queja escolar; Educación; Orientación Educacional. 


\section{Introdução}

A teoria e a prática da psicologia escolar no Brasil vêm passando por transformações que nas últimas décadas têm demonstrado a relação da queixa escolar com a situação de reprovação e exclusão escolar do sistema educacional. Tais mudanças dizem respeito à compreensão de que a abordagem clínica individual da psicologia escolar não contempla os aspectos sociais construídos historicamente no cotidiano das escolas. Também compreendemos isso quando da coordenação e supervisão de estágios em psicologia escolar e educacional.

Nessa experiência ouvimos de professores, direção, supervisão e orientação escolar, reclamações de que não há psicólogos nas escolas, e que é difícil conseguir atendimento para os alunos com queixa escolar. Alegam que, se os alunos passassem por um atendimento psicológico e tivessem uma avaliação, seria possível à escola reorganizar-se em torno das queixas escolares.

Por queixa escolar compreende-se aqui não só as dificuldades de aprendizagem, mas todo fato da dinâmica escolar que se torna um lamento na fala de professores, direção, supervisão e orientação, como a indisciplina, agressividade, sexualidade, entre outros. (M. P. R. Souza, 2000, 2005; Machado, 1998, 2000).

Como resultado dessa vivência, surgiu a seguinte proposição: como as escolas têm se organizado para a discussão e enfrentamento da queixa escolar a partir dos retornos recebidos dos atendimentos psicológicos? Que atitudes têm sido tomadas a partir das orientações recebidas nessas devolutivas?

Para tanto, procuramos conhecer como são realizados os atendimentos psicológicos aos alunos da rede municipal de Ariquemes (RO), encaminhados com queixa escolar ao serviço de atendimento psicológico, e quais ações têm ocorrido na escola a partir das devolutivas.

A psicologia escolar crítica, que constitui a base teórica de nossa pesquisa, demonstra que é possível compreender a queixa escolar como um processo construído historicamente na inter-relação dos atores escolares dentro do sistema educacional e propõe uma mudança de perspectivas que não é de culpabilização. "Mudamos a pergunta, em vez de nos dirigirmos a pessoas ou situações isoladas - o que tem efeito paralisador - buscamos as circunstâncias, porque estas podem ser transformadoras" (Tanamachi \& Meira, 2003, p. 32).

Por isso, acreditamos que, se as escolas realmente se propuserem a repensar a produção da queixa escolar, de alguma forma, que pode ser a partir das devolutivas dos atendimentos psicológicos, poderão estabelecer novas estratégias para enfrentamento da queixa escolar e de outras problemáticas da complexidade do cotidiano educacional.

\section{Metodologia}

A pesquisa foi desenvolvida nas escolas municipais de ensino fundamental de Ariquemes (RO) e em um Núcleo de Saúde (municipal), para o qual são encaminhados os alunos com queixa escolar, no período de 2008 a 2010. Ela consistiu de análise documental dos encaminhamentos e laudos (devolutivas, inclusive particulares) e entrevista com as orientadoras e a psicóloga que realizou os atendimentos.

O levantamento foi realizado nas 14 escolas urbanas de ensino fundamental, porém só foram entrevistadas as nove orientadoras que tiveram pelo menos um retorno. Focalizamos a pesquisa nas escolas urbanas, pois não havia alunos da zona rural.

Iniciamos a pesquisa após autorização do Comitê de Ética na Pesquisa do Núcleo de Saúde (NUSAU), da Universidade Federal de Rondônia (UNIR) e com a autorização da Secretaria Municipal de Educação de Ariquemes (SEMED). O procedimento para a análise dos dados se deu através da análise de conteúdo.

\section{Apresentação e Análise dos Dados}

O Núcleo de Saúde foi inaugurado em 19 de março de 2008 e atende, além do município de Ariquemes, nove municípios do entorno. São mais de 1.500 procedimentos por mês, com profissionais na área de psicologia, fonoaudiologia, fisioterapia e terapia ocupacional. Antes da inauguração do Núcleo, os alunos não tinham destino certo para serem encaminhados e eram mandados para qualquer psicólogo do município em que se acreditava ter vaga, como por exemplo, em postos de saúde.

\section{As Escolas - Caracterização}

Foram pesquisadas as 14 escolas municipais urbanas, aqui nomeadas pelos números naturais. As escolas 3 , $4,9,10,11,13$ e 14, oferecem até o $5^{\circ}$ ano e as demais até o $9^{\circ}$ ano. Apenas as escolas 9, 10, 13 e 14 oferecem também Educação Infantil e somente as escolas 9, 10 e 11 não oferecem a Educação de Jovens de Adultos.

As escolas 1, 2, 3, 7, 9, 10, 11, 13 e 14 foram as instituições que fizeram encaminhamento dos alunos para o atendimento psicológico e tiveram pelo menos um retorno cada uma. As escolas 4 e 8 também realizaram encaminhamentos, mas não obtiveram nenhum retorno. A escola 6 afirmou não ter feito nenhum encaminhamento no período, pois nunca tiveram retornos dos profissionais. As escolas 5 e 12 também não haviam tido retorno dos encaminhamentos, mas mesmo dos encaminhamentos realizados não nos forneceram os dados.

As escolas pesquisadas atendem entre 500 e 1060 alunos (E3-550; E10-561; E13-878; E2-1059) e o fazem com uma média de 50 funcionários (E2-28; E7-47; E13-54; E174). As Escolas 1, 10, 13 e 14 ficam na região central da cidade e as Escolas 2, 3, 7, 9 e 11 na periferia.

Não encontramos situação precária em nenhuma das escolas, apenas nas escolas 1, 3, 9, 10, 11, 13 e 14, pode-se ver mais espaço e organização do que nas escolas 2 e 7 , inclusive a escola 1 é a que tem maior número de 
funcionários (74). Há condições adequadas para o trabalho escolar, como refeitórios, nutricionistas, sala de direção, mas que precisam e podem ser melhoradas na maioria das instituições, principalmente no que tange aos espaços de gestores educacionais. Em apenas uma escola a sala da Orientação Escolar é ampla. Em geral a sala é dividida com outros profissionais e sempre há caixas de material escolar empilhados. A E2 ainda tem uma parte do pátio em chão de terra, e a E7 faz uso da quadra de esportes na instituição em frente à escola.

Muitos espaços foram reservados ao Programa Mais Educação, que são oficinas no contra turno, para atender alunos num esforço de projeto de escola integral do governo municipal. Em algumas escolas, como a E1, poucos alunos aderiram ao programa e apenas 80 ficam no contra turno, já na E7, todos os alunos ficam no contra turno. A E11 também oferece o Programa Segundo Tempo, que tem a mesma finalidade que o Mais Educação, apenas as oficinas oferecidas são diferentes.

A E14 tem o diferencial de, tendo estimulado um convênio entre Prefeitura e uma faculdade particular da cidade, ter uma estagiária de psicologia, supervisionada por um professor da IES, que atende os alunos todas as tardes, por isso não encaminha alunos para o Núcleo de Saúde.

\section{Encaminhamentos e devolutivas do atendimento psicológico para as escolas}

A Tabela 1 reúne as informações de encaminhamentos e devolutivas do atendimento psicológico das Escolas 1, $2,3,7,9,10,11,13$ e 14 no período de 2008 a 2010 e da
E11 no também no período de 2004 a 2007, que foi a única a ter o material organizado à disposição para pesquisa. Não tivemos acesso direto aos documentos, pois alegavam as escolas que o mesmo não estava organizado.

No exame particular dos dados, percebe-se um aumento de encaminhamentos entre os anos de 2008-2009 e 2009-2010, especialmente no $1^{\circ}$ e $2^{\circ}$ anos (7, 16 e 58; 15, 45 e 69 respectivamente), que se justifica pelo fato de o Núcleo de Saúde ter sido implantado em março de 2008. No ano de 2009 também se observa um aumento dos encaminhamentos no $3^{\circ}, 4^{\circ}$ e $5^{\circ}$ anos, de aproximadamente $400 \%$, caindo em $70 \%$ em 2010 . Outros índices significativos não foram percebidos.

Machado (2003) afirma que quando existe a possibilidade de a escola ter acesso ao psicólogo ocorre uma intensificação de expectativas e procura. Os educadores querem saber por que a criança não aprende ou porque apresenta determinados comportamentos e, por isso, recorrem ao psicólogo. Foi isso exatamente o que aconteceu com a criação do Núcleo de Saúde Municipal em 2008, quando passou a haver uma profissional disponível para atender os encaminhamentos das escolas.

A 010, quando questionada quanto ao aumento do número de encaminhamentos feitos no ano de 2010 em relação ao de 2009, afirmou que a clientela da escola tinha mudado muito e que agora estavam atendendo também crianças de bairros periféricos, de população carente, e com isso tinha crescido o problema. "Eles vêm com muitos problemas, nossa! É uma população muito problemática: pais separados, abusos. É por isso que teve esse aumento de encaminhamento, a gente não sabe lidar com essa clientela com esses problemas, aí a gente encaminha".

Tabela 1. Encaminhamentos e Retornos de Atendimentos das Escolas Municipais Urbanas de Ariquemes ao Núcleo de Saúde entre $2008-2010$.

\begin{tabular}{cccc}
\hline Ano Escolar & Encaminhamentos & Retornos & Sem Retornos \\
\hline Pré I & 7 & 3 & 6 \\
\hline Pré II & 11 & 24 & 67 \\
\hline $1^{\circ}$ & 91 & 22 & 115 \\
\hline $2^{\circ}$ & 137 & 18 & 75 \\
\hline $3^{\circ}$ & 93 & 13 & 55 \\
\hline $4^{\circ}$ & 68 & 6 & 52 \\
\hline $5^{\circ}$ & 58 & 1 & 14 \\
\hline $6^{\circ}$ & 15 & 2 & 6 \\
\hline $7^{\circ}$ & 8 & & 3 \\
\hline $8^{\circ}$ & 3 & & 18 \\
\hline Sem ano espec. & 18 & & \\
\hline
\end{tabular}

Fonte: Dados da pesquisa. 
Nessa fala ficam evidentes o preconceito e a segregação feita com os alunos que são das classes menos favorecidas economicamente. A psicologia escolar crítica afirma que a escola pública é permeada de preconceitos, discriminação e desigualdade entre os alunos da classe menos favorecida economicamente (Patto, 1997, 2005; Collares \& Moysés, 1996; Moysés, 2005; B. P. Souza, 2007; Gonçalves Filho, 2007).

O número total de encaminhamentos também é significativo, seja por ano ou por escola, inclusive desde os anos iniciais da Educação Infantil, e isso infelizmente não é singularidade de Ariquemes. Em pesquisa realizada por Proença (2004), especificamente em oito unidades básicas de saúde (UBS), obteve-se como resultado que $70 \%$ dos encaminhamentos realizados para atendimento psicológico - faixa etária entre cinco a 14 anos - apresentavam, como queixas, problemáticas referentes ao processo de escolarização. $\mathrm{E}$ mais, o número de encaminhamentos de alunos com queixa escolar ao Serviço de Psicologia Escolar do Instituto de Psicologia da USP é muito grande, nos quais existem muitos pedidos de avaliação psicológica (Machado, 2004).

Por fim, não poderíamos deixar de comentar o número de retornos apresentados à escola, que é muito inferior ao número de encaminhamentos. Acreditamos que isso se dê por dois motivos: a grande demanda de encaminhamentos, e a falta de interesse da escola por um retorno da psicóloga. Como a psicóloga entrevistada afirma: "Eu não retorno. Só retorno quando eles pedem e como nunca pedem...". Mas pensamos que se o aluno é encaminhado para atendimento psicólogo, está intrínseca a necessidade do retorno.

\section{Entrevista com as Orientadoras}

Os resultados das entrevistas com as Orientadoras foram organizados em três categorias: encaminhamentos, retornos dos atendimentos e organização das escolas. $\mathrm{Na}$ categoria encaminhamentos, procuramos compreender os critérios utilizados pelas escolas para o encaminhamento, bem como os procedimentos realizados. Na categoria retornos, incluímos a descrição das devolutivas às escolas por meio de laudos ou relatórios. Na categoria organização está a reorganização escolar para a discussão e enfrentamento da queixa escolar.

\section{Encaminhamentos}

Em todas as escolas a queixa parte do professor, é ele quem traz para o orientador a situação-problema do aluno. O professor é visto como aquele que sabe diagnosticar o problema do aluno. $\mathrm{E}$ isso pode ser verificado na fala da $\mathrm{O} 2$ : "Eu acho que a própria prática dá esse direito pra eles... ele já tem conhecimento de causa".

Collares e Moysés (1996) discutem que o caráter autorrealizador da opinião dos professores ao longo do pro- cesso pedagógico implica na desistência do professor por esse aluno.

As autoras verificaram também que são poucos os educadores que se incluem no processo ensino-aprendizagem e consequentemente não se veem como responsáveis pelo fracasso escolar. Apenas a $\mathrm{O} 13$ relatou que uma professora, ao encaminhar seu aluno, pediu ajuda para si: "A professora estava perdida. Não sabia por que a criança estava desmotivada. Achava que era a aula dela". A orientadora relatou tal fato julgando a professora como insegura, não considerando que era pertinente questionar-se.

A partir do momento em que recebem a queixa, a maioria (6) chama imediatamente os pais; há uma conversa com a criança e depois chama os pais; uma conversa com a criança, depois com a professora e depois chama os pais e uma encaminha imediatamente para atendimento psicológico. Verificamos também que nenhuma orientadora, com exceção de 013, que fez isso (apenas) uma vez, se reúne primeiramente com o professor para saber melhor o que está acontecendo.

Assim como na pesquisa de Zibetti, Souza, e Queiróz (2007), o professor desaparece do cenário de discussão da queixa escolar logo após encaminhar o aluno para a orientação. Excluído de todo o processo de encaminhamento e investigação sobre a queixa escolar, não é questionado sobre os processos pedagógicos, comparações com o desempenho da turma, discutir sobre o histórico escolar da criança ou sobre o que vem observando da psicodinâmica da sala de aula, entre outros aspectos pertinentes à dinâmica escolar envolvidos na queixa.

$\mathrm{Na}$ E14, apesar de terem uma estagiária de psicologia atendendo às demandas da escola, verificamos que o processo de encaminhamento é idêntico.

\section{Retornos}

Das nove orientadoras entrevistadas, seis reclamaram que os retornos dos atendimentos com a psicóloga são mínimos. Entre as três orientadoras que não reclamaram dos retornos, está 014, que é da escola que fez parceria com a Prefeitura para conseguir estagiários de psicologia que atendem na escola; a 07 , que afirmou que pelo menos três vezes ao ano vai à psicóloga perguntar sobre os alunos encaminhados; e a 02 , que não vai até a psicóloga, mas pressiona muito os pais para levarem o laudo.

Alegam que nem sempre conseguem compreender o que os laudos querem dizer e por isso gostariam que a psicóloga fizesse esse retorno pessoalmente. "Infelizmente, os psicólogos são muito ocupados e não podem vir para a escola e nós também não podemos ir". (09 e 010). Na escola com a estagiária de psicologia, os retornos são pessoais e por isso mais positivos, segundo 014 .

Encontramos na fala das orientadoras que a família é a responsável em acompanhar os filhos ao atendimento psicológico e trazer o retorno para a escola. A O2 afirmou 
que só havia muitos retornos, porque cobrava dos pais: "Tem que convencer, tem que ameaçar. Hoje nós temos mais recursos, hoje nós temos o promotor".

As orientadoras também não concordam com as informações recebidas no laudo, já que as informações são obtidas pela psicóloga durante os atendimentos às famílias, sem ir às escolas.

Em certa medida, temos que concordar com as orientadoras, já que a ausência da psicóloga que atende os encaminhamentos de queixa escolar na escola priva-lhes de um olhar mais amplo sobre o dia a dia escolar e as inter-relações estabelecidas na instituição, gerando insatisfação e dúvidas quanto à fidedignidade de seu trabalho (Loureiro, 1997). Se antes era possível à psicologia ficar longe, num espaço distante da escola, hoje essa atitude não é bem vista (Kupfer, 2004).

As orientadoras também reclamaram que os retornos não trazem informação referente a como agir com o aluno: "Às vezes até percebemos alguma melhora na criança, não há comunicação entre a escola e a psicóloga e a gente fica perdida". (E3).

O que está em questão, na verdade, é analisar as mudanças necessárias, na maioria das vezes, nas relações cotidianas. É preciso conscientizar-se de que a aprendizagem se dá num processo de ensino, é uma via de mão dupla (Machado, 2004).

\section{Organização e acompanhamento na escola a partir dos retornos do atendimento psicológico}

A primeira atitude tomada, por oito orientadoras entrevistadas, é chamar o professor e repassar as orientações feitas pela psicóloga. "A primeira coisa é chamar o professor. Ele tem que estar ciente de como aquele aluno aprende" (O2). "Eu chamo o professor, xeroco o papel que vem da psicóloga e mando ele (sic) trabalhar com o aluno igual está aí no papel e só isso" (01).

As orientadoras alegaram que passam para o professor trabalhar porque não têm tempo: "Tudo é tão corrido, que na grande maioria das vezes não consigo acompanhar o aluno como eu gostaria" (O3).

A 09 encaminha direto para a sala de recursos e depois comunica o professor. Outras cinco encaminham para as orientadoras, depois de conversar com os professores, chamam os pais, para passar para eles as informações do laudo. "Depois do retorno, a escola não faz nada. Conversa com os pais e com a professora e só, não tem como fazer nada, não dá tempo" (010). As demais, quatro orientadoras, limitam-se aos professores e o encaminhamento à sala de recursos.

As orientadoras não conseguem se perceber implicadas no processo de aprendizagem ou de fracasso do aluno, como se a justificativa da falta de tempo fosse suficiente para sustentar a falta de ação da escola em questões essenciais.

O encaminhamento para a sala de recursos também acontece antes de ter o retorno do atendimento. "Às vezes, quando o retorno demora, a gente já encaminha para a sala de recurso pra não perder tempo" (O2). Percebemos que a sala de recursos é vista como a solução para o aluno com queixa escolar, e que é o suficiente para que consiga aprender: "Lá ele vai ter um atendimento que nem o do psicólogo, dentro das possibilidades dele" (O1). Quando a escola não tem sala de recurso isso é um problema na visão das orientadoras, pois a solução que havia sido encontrada antes não é possível.

Quanto ao acompanhamento dos alunos depois do retorno do atendimento psicológico, ficou evidente nas falas de cinco orientadoras que não havia nada efetivo: "Às vezes a professora vem mostrar o caderno que ele melhorou, mas não é feito nada, não tem tempo, é muito trabalho" (010). Duas orientadoras disseram que tentam acompanhar conversando com os professores, às vezes, até jogam com os alunos, mas que isso somente ocorre eventualmente: "Muitas vezes eu trabalho aqui na minha sala com esse aluno, ou a professora faz uma atividade diferente para todos da sala. Mas isso é muito difícil acontecer, pois são muitos alunos e uma atividade assim é difícil de ser aplicada para muitos" (O3).

A 014 afirma que acompanha os alunos por meio de observações na sala, no pátio, conversando com os professores e fazendo visitas domiciliares aos pais. "A gente sempre conversa com os pais, com os professores; vamos até na casa do aluno, ficamos observando ele no pátio para ver se ele melhorou". As visitas domiciliares são, na verdade, para conversar com os pais e determinar o que devem fazer para ajudar a escola.

Portanto, não percebemos nenhuma discussão da queixa escolar na escola que os casos encaminhados ao atendimento psicológico ou os laudos de retorno tenham suscitado, apenas os professores que fizeram os encaminhamentos fizeram um replanejamento para atender o aluno. Inferimos de Machado (s. d.), que assim como os encaminhamentos, a alegação da falta de tempo é resultado da forma como as relações se dão no espaço escolar.

a maioria dos encaminhamentos que vêm da área da educação para especialistas tem relação com a pouca possibilidade de discussão, de poder pensar em hipóteses sobre o que ocorre e criar estratégias sobre o que fazer no cotidiano escolar... Também não podemos pensar na falta de tempo como causa... pois ela já é efeito de uma maneira de estruturar os tempos e espaços da escola... Quando essa célula da escola - que a nosso ver é a sala de aula, e não o aluno - não pode ser pensada, resta a cada professor recorrer às suas estratégias pessoais, e o que temos visto é que a intervenção no coletivo e o cuidado com os acontecimentos em determinada classe ficam impedidos (p. 7).

\section{Entrevista com a Psicóloga do Núcleo de Saúde Municipal}

A psicóloga entrevistada nos explica que são muitos os encaminhamentos feitos pelas escolas, e que a demanda é maior do que sua capacidade de atendimento. Por serem 
14 escolas municipais que atendem o ensino fundamental, além das de ensino médio, a fila de espera é grande. "Eles querem que você resolva o problema sozinha e não assumem nenhuma responsabilidade".

A posição da psicóloga para atender aos casos de crianças encaminhadas pelas escolas é indiscutivelmente clínica: "Eu faço uma avaliação psicológica com cada criança, isso de clínica mesmo. Anamnese, ludoterapia, teste de HTP, teste de inteligência com a figura humana e de inteligência não verbal com o INV", bem como não faz nenhum contato com a escola para esse diagnóstico, como conhecer a escola ou conversar com o professor da criança encaminhada: "Não, eu não vou à escola; se eu preciso de alguma informação da escola, isso é feito através dos pais".

Para os atendimentos, usa ludoterapia de orientação analítica e declara sua paixão pela psicanálise e nos afirma que conhece outras teorias e instrumentos, mas que considera esta a melhor forma, já que teria experimentado outras, mas não se sentia satisfeita com elas:

A escola quer que você atenda de qualquer maneira e, sendo assim, eu tentava fazer atendimento em grupo de crianças e, às vezes, ia pra escola só para fazer triagem, para dar a ideia que estava atendendo. Fazia algumas orientações com os pais, e só, não tem jeito de fazer outra coisa [...] Eu trabalho o lado emocional do aluno, pois nessa situação... o que isso pode causar nele é autoestima baixa e aí eu trabalho no sentido de fortalecimento emocional e autoestima.

Embora tendo escolhido uma linha teórica tradicional, é possível fazer um trabalho não pautado em práticas clínicas tradicionais. Kupfer (2004) explica sobre a possibilidade da utilização da psicanálise na escola de forma crítica, contribuindo para criar novas condições de entender o fracasso escolar por intermédio de todos os atores, e não somente do aluno.

O trabalho do psicólogo deveria ser efetuado com a construção e histórico da queixa escolar, voltando-se verdadeiramente para ela. O objetivo deveria ser movimentar e investigar a queixa escolar na escola, com todos os atores escolares, assumindo assim, uma atitude ativa, de interação, de busca coletiva, de discussão (B. P. Souza, 2007; Checchia \& Souza, 2003).

Recorremos a Machado e Souza (2004) para argumentar sobre a possibilidade de um trabalho coletivo para esse profissional:

Em vez de perguntarmos à mãe, em uma anamnese a respeito de um dia na rotina da criança, precisamos conhecer como a professora entende os problemas de seu aluno, dando informações sobre o contexto de sala de aula. Em vez de colhermos informações sobre os primeiros meses de vida da criança, podemos obter dados sobre sua história escolar, sobre a classe em que está (critérios de formação), por exemplo, e o que pensa sobre as queixas feitas pela professora. Em vez de aplicarmos testes de inteligência e projetivos, formamos pequenos grupos nos quais são criados espaços de expressão e comunicação, em que a criança fala de seu aprendizado, de sua vida escolar e mostra as suas potencialidades cognitivas e expressivas. Paralelamente, trabalhamos com as professoras que encaminham as crianças (p. 52).

Entendemos que a situação da entrevistada, ao trabalhar fora do ambiente escolar, em um núcleo de saúde, dificulta algumas dessas ações, mas não sendo esta uma realidade exclusiva dela, muitas instituições e profissionais têm discutido opções críticas para núcleos de saúde e outros atendimentos médicos para onde são encaminhados os casos de queixa escolar.

Para atender em instituições de grande demanda, Severo (1993) nos apresenta diversas opções, como grupos de espera e grupos operativos, e no acompanhamento da queixa escolar, tem apresentado resultados significativos, o plantão institucional (Machado, 2007). Este dispositivo institucional poderia trazer ao núcleo de saúde as equipes das escolas que encaminham alunos para atendimentos e a psicóloga poderia discutir com eles a produção da queixa e projetos para a escola a partir das discussões com o próprio grupo.

Causa-nos estranhamento a profissional não ter achado válida a experiência com grupo de crianças, já que isso vai de encontro às diversas experiências relatadas no Brasil que demonstram resultados positivos com essa estratégia (Machado, 2004; Freller, 2004; Leandrini \& Saretta, 2007) e para não deixar de dar exemplos regionais, próximos da realidade da entrevistada, resultados semelhantes encontraram Minin e Leite (2011).

Consideramos, principalmente, que os grupos de alunos modificam o ponto de vista do profissional da psicologia acerca do estigma que os alunos carregam.

Submetidas a um olhar crítico, constatamos o quanto as queixas escolares se mostram inconsistentes, fragilidade esta notadamente visível ao interagirmos com os alunos encaminhados, os quais mostravam um domínio dos conhecimentos básicos, potencial de criatividade, discernimento das regras estabelecidas no grupo e boa relação com os demais colegas. (Minin \& Leite, 2011, p. 20.).

Agindo assim, a psicóloga firma compromisso com a produção do fracasso escolar dos alunos que não se enquadram no padrão predeterminado pelos educadores, mantendo a posição de transferirem a responsabilidade da queixa escolar, não buscando a compreensão da queixa de forma geral (Fernandes \& cols., 2007).

Alguns autores da psicologia escolar crítica (M. P. R. Souza, 1996; Neves, 2007; Sampaio, 2007; Marinho-Araújo \& Neves, 2007) afirmam que a formação do profissional da psicologia é um dos fatores responsáveis pelo modelo tradicional clínico utilizado pelo psicólogo no ambiente escolar. Quando, porém, questionada a respeito de sua formação, a psicóloga respondeu: "Eu tive psicologia escolar, crítica mesmo. Estudei Patto, atendimento com grupo nas escolas. 
Mas é impossível fazer isso na escola... E por isso pedi para ir para o atendimento clínico".

Concordamos com Martínez (2005, citada por Carvalho \& Marinho-Araújo, 2009), quando afirma que a competência técnica do psicólogo é secundária e que o grande desafio do psicólogo escolar, perante a demanda da verdadeira inclusão escolar, refere-se a escolher atuar a partir do compromisso com a classe menos favorecida e com alunos que são rotulados e classificados por não condizerem com o padrão de normalidade estabelecido pelos educadores.

Quanto aos retornos, a psicóloga explicou que as escolas nunca procuravam o núcleo de saúde para saber os resultados do atendimento. "Na verdade, a escola quer que a gente atenda os alunos e que resolva o problema deles e só isso; resolvendo, está bom" e que, portanto não retorna; "Eu não retorno. Só retorno quando eles pedem e como nunca pedem...". Normalmente faz a devolução aos pais, passando orientações.

"Às vezes eles querem saber como ensinar o aluno. Faça-me o favor, eu não sou pedagoga, isso é papel de pedagogo, eu não sei como se deve ensinar as crianças. Eu só falo do trabalho que eu faço com eles, e só".

Nossa conclusão da entrevista com a profissional é que ela, em sua prática, não tem contribuído para superar a exclusão e o preconceito existente na escola na produção da queixa escolar, que culpabiliza e marginaliza alunos e familiares e muitas vezes, fortalece esse estigma.

Apesar de declarar conhecer a literatura da psicologia escolar crítica, segue sem propor a compreensão da complexidade do dia a dia escolar de seus atores. Acreditamos que se sente mais segura em atender clinicamente, fora do campo de tensões que pode se criar no cotidiano da escola.

Tada, Sapia e Lima (2010) estudaram a formação e prática de psicólogos em Rondônia e compreenderam que muitos profissionais se apresentam assim, convictos de que os instrumentos são realmente esses, embora tenham tido contato com a literatura da psicologia escolar crítica. Esses resultados são compreendidos de forma qualitativa quando Donato, Lima e Tada (2011) demonstram que o psicólogo escolar deixa de atuar na escola e pede transferência para a saúde porque não se sente identificado com essa instituição.

\section{Conclusão}

Esta pesquisa teve por objetivo compreender o processo de organização escolar a partir dos retornos dos encaminhamentos de alunos com queixa escolar para acompanhamento psicológico. Os resultados demonstram que não há modificação no enfrentamento da queixa escolar nas escolas a partir dos retornos da psicóloga (que são poucos). Sustentamos essa afirmação no fato de as orientadoras afirmarem: "Não faço nada, não dá tempo, são muitos alunos na escola, não dá para cuidar de todos" (01). "Na verdade é bem difícil. Tem tanto trabalho para realizar que um acompanhamento efetivo nós não conseguimos" (O3). "Não, não é feito um trabalho sistematizado para acompanhar o aluno"
(O9). "Depois do retorno, a escola não faz nada. Conversa com os pais e com a professora e só" (010).

Os resultados não apontam nenhuma diferença significativa nas justificativas dos encaminhamentos ou no trato com os retornos entre as escolas centrais do município ou periféricas, mas em todos os encaminhamentos há uma culpabilização do aluno e sua família, onde existe um alegado desajuste que reflete na escola.

Programas como o Mais Educação e Segundo Tempo, que existem em todas as escolas pesquisadas, e são um esforço do governo municipal de implantar uma educação de tempo integral, embora a estrutura ainda deixe a desejar, sequer são citados como recursos ou estratégias, pelo menos para apoio às famílias, já que se alega a falta de estrutura destas.

Com relação à motivação dos encaminhamentos de queixa escolar, percebemos que ocorre pela busca da homogeneidade no comportamento dos alunos: o diferente deve ser trabalhado pelo psicólogo e depois acompanhado pelos técnicos da sala de recursos, ao que os profissionais que têm feito os atendimentos (psicóloga do núcleo de saúde e estagiária de psicologia numa das escolas) colaboram.

$\mathrm{Na}$ responsabilização da queixa escolar há a culpabilização dos alunos e de seus pais, a quem as orientadoras referiam-se como descompromissados e ausentes afetivamente e na prática de valores humanos. Em síntese, podemos argumentar que, na visão das entrevistadas, e não tememos dizê-lo, das escolas que participaram da pesquisa, o não aprendizado tem como responsável o próprio aluno ou sua família.

O papel do psicólogo referenda o diagnóstico dos professores e ajuda a rotular e discriminar o aluno. A escola quer respostas e o profissional submete-se a dá-las. A possibilidade de fazer um encaminhamento para o psicólogo amplia as expectativas dos professores e da escola que alguém extraescola vá resolver o problema. Sendo assim, foi perceptível que em muitas circunstâncias as instituições têm uma tendência de transferir responsabilidades ao psicólogo de medidas que convêm e deveriam ser realizadas na própria escola.

Há muito Ceccon, Oliveira e Oliveira (1998) denunciam a escola como um lugar no qual todos se queixam e criticam o funcionamento, mas ninguém se vê parte dessa dinâmica. Infelizmente também encontramos esses resultados nas escolas pesquisadas. O que fica evidente é que se transfere a responsabilidade sem pensar coletivamente sobre a construção da queixa escolar, situação que se mantém nas escolas pesquisadas.

Não há na escola espaços para a discussão sobre a queixa escolar. A responsabilidade do aluno com queixa escolar é passada para o professor do aluno ou para o professor da sala de recursos. Não se problematiza a complexidade do dia a dia da queixa escolar. Não se discute a sistemática pedagógico-institucional, que em muitos casos pode e necessita rever e redimensionar metodologias para ir ao encontro das novas demandas e necessidades educacionais. 
A escola precisa ser compreendida como uma instituição inserida em uma contextualização sociocultural, capaz de atender às demandas de seu tempo, respeitando as diferenças, promovendo processos de ensino-aprendizagem inclusivos, com o auxílio do psicólogo, quando se fizer necessário.

Há mais de 30 anos dos primeiros escritos de Moysés e Lima (1982) e há mais de 20 anos das pesquisas críticas iniciais de Patto (1997), ainda vemos os problemas relacionados ao sistema educacional brasileiro se repetirem, de Norte a Sul do Brasil. A literatura e as experiências em psicologia escolar crítica com atitudes revolucionárias já existem, assim como eventos que discutem e divulgam essas novas ideias, mas a postura política de muitos profissionais ainda não se modificou, inferimos disso que é urgente a modificação dos currículos universitários enfocando a formação crítica (e social) nos cursos de Psicologia brasileiros, bem como espera-se dos gestores educacionais sistemas de suporte e acompanhamento mais estruturados para discutir e enfrentar a queixa escolar.

\section{Referências}

Carvalho, T. O. \& Marinho-Araújo, C. M. (2009). Psicologia escolar no Brasil e no Maranhão: percursos históricos e tendências atuais. Psicologia Escolar e Educacional, 13(1), 65-72.

Ceccon, C., Oliveira, M. D., \& Oliveira, R. D. (1998). A vida na escola e a escola da vida (14a ed.). Petrópolis, RJ: Vozes.

Checchia A. K. A. \& Souza, M. P. R. (2003). Queixa escolar e atuação profissional: apontamentos para a formação de psicólogos. Em M. E. M. Meira \& M. A. M. Antunes (Orgs.), Psicologia escolar: teorias críticas (pp. 105-137). São Paulo: Casa do Psicólogo.

Collares, C. A. L. \& Moysés, M. A. A. (1996). Preconceitos no cotidiano escolar: ensino e medicalização. São Paulo: Cortez; Campinas: UNICAMP/Faculdade de Educação/Faculdade de Ciências Médicas.

Donato, S. E. M., Lima, V. A. A., \& Tada, I. N. C. (2011). O processo de inclusão na visão de professores das séries iniciais do ensino fundamental. Em V. A. A. Lima \& R. M. C. Pereira (Orgs.), Recortes teóricos práticos da psicologia (pp. 91-103). Curitiba: CRV.

Fernandes, Â. M. D., Moura, A. A., Sousa, D. M. F., Patriota, G. F., Araújo, J. M. A., \& França, M. L. P. (2007). Histórias e práticas do sofrer na escola: múltiplos atos/atores na produção do "alunoproblema”. Em Â. M. D. Fernandes, M. L. Rocha, \& A. Marcondes (Orgs.), Novos possíveis no encontro da psicologia com a educação (pp. 145-166). São Paulo: Casa do Psicólogo.

Gonçalves Filho, J. M. (2007). Humilhação social: humilhação política. Em B. P. Souza (Org.), Orientação à queixa escolar (pp. 187-221). São Paulo: Casa do Psicólogo.
Freller, C. C. (2004). Grupos de crianças com queixa escolar: um estudo de caso. Em A. M. Machado \& M. P. R. Souza (Orgs.), Psicologia escolar: em busca de novos rumos (pp. 127-141). São Paulo: Casa do Psicólogo.

Kupfer, M. C. M. O que toca à/a psicologia escolar. Em A. M. Machado \& M. P. R. Souza (Orgs.), Psicologia escolar: em busca de novos rumos (pp. 378-398). São Paulo: Casa do Psicólogo.

Leandrini, K. D. \& Saretta, P. (2007). Atendimento em grupo de crianças com queixa escolar: possibilidades de escuta, trocas e novos olhares. Em B. P. Souza (Org.), Orientação à queixa escolar (pp. 379-398). São Paulo: Casa do Psicólogo.

Loureiro, M. C. S. (1997). Psicologia escolar: mera aplicação de diferentes psicologias à educação? Em M. H. S. Patto (Org.), Introdução à psicologia escolar (3a ed.). (pp. 449-458). São Paulo: Casa do Psicólogo.

Machado, A. M. (s.d.). A produção de desigualdades nas práticas de orientação. Recuperado: 29 fev. 2016. Disponível: http://www2. fe.usp.br/ cpedh/Desigualdade $\% 20$ e $\% 20$ Educ $\% 20$ Adriana $\% 20$ Marc.pdf.

Machado, A. M. (1998). Avaliação e Fracasso: a produção coletiva da queixa escolar. Em J. G. Aquino (Org.), Erro e Fracasso na Escola: alternativas teórico práticas (2a ed.). (pp. 73-79). São Paulo: Summus.

Machado, A. M. (2000). Avaliação psicológica na educação: mudanças necessárias. Em E. R. Tanamachi, M. Proença, \& M. L. Rocha. (Orgs.), Psicologia e educação: desafios teórico-práticos (pp. 143-168). São Paulo: Casa do Psicólogo.

Machado, A. M. (2003). Os psicólogos trabalhando com a escola: intervenção a serviço do quê? Em M. E. M. Meira \& M. A. M. Antunes (Orgs.), Psicologia escolar: práticas críticas (pp.63-85). São Paulo: Casa do Psicólogo.

Machado, A. M. (2004). Relato de uma intervenção na escola pública. Em A. M. Machado \& M. P. R. Souza. (Orgs.), Psicologia escolar: em busca de novos rumos (pp. 93-103). São Paulo: Casa do Psicólogo.

Machado, A. M. (2007). Plantão institucional: um dispositivo criador. Em Â. M. D. Fernandes, M. L. Rocha, \& A. M. Machado (Orgs.), Novos possíveis no encontro da psicologia com a educação (pp. 117-143). São Paulo: Casa do Psicólogo.

Machado, A. M. \& Souza, M. P. R. (2004). As crianças excluídas da escola: um alerta para a psicologia. Em A. M. Machado \& M. P. R. Souza (Orgs.), Psicologia escolar: em busca de novos rumos. (pp. 39-54). São Paulo: Casa do Psicólogo.

Marinho-Araújo, C. M. \& Neves, M. M. B. J. (2007). Psicologia escolar: perspectivas e compromissos na formação continuada. Em H. R. Campos. (Org.), Formação em psicologia escolar: realidades e 
perspectivas (pp. 69-87). Campinas: Alínea.

Minin, J. C. \& Leite, L. F. (2011). Compreendendo a queixa escolar em uma perspectiva crítica: relato de experiência junto a um grupo de crianças. Em V. A. A. Lima \& R. M. C. Pereira (Orgs.), Recordes teóricos práticos da psicologia (pp. 9-22). Curitiba: CRV.

Moysés, M. A. A. (2005). A institucionalização invisível: crianças que não aprendem na escola. Campinas: Mercado das Letras.

Moysés, M. A. A. \& Lima, G. Z. (1982). Desnutrição e fracasso escolar: uma relação tão simples? Revista da Andrés, 5.

Neves, M. M. B. J. (2007). Formação inicial em psicologia escolar: questões apontadas por alunos de graduação. Em H. R. Campos. Formação em psicologia escolar: realidades e perspectivas (pp. 49-68). Campinas: Alínea.

Patto, M. H. S. (1997). Da psicologia do "desprivilegiado" à psicologia do oprimido. Em M. H. S. Patto, Introdução à psicologia escolar (3a ed.). (pp. 257-296). São Paulo: Casa do Psicólogo.

Patto, M. H. S. (2005). Exercícios de indignação: escritos de educação e psicologia. São Paulo: Casa do Psicólogo.

Sampaio, S. M. R. (2007). A educação e a educação do psicólogo: ideias e práticas de pesquisa-ação-formação. Em H. R. Campos (Org.), Formação em psicologia escolar: realidades e perspectivas (pp. 89-106). Campinas: Alínea.

Severo, M. C. (1993). Estratégias em psicologia institucional. São Paulo: Loyola.
Souza, B. P. (2007). Apresentando a orientação à queixa escolar. Em B. P. Souza (Org.), Orientação à queixa escolar (pp. 97-117). São Paulo: Casa do Psicólogo.

Souza, M. P. R. (1996). A queixa escolar e a formação do psicólogo. Tese de Doutorado, Instituto de Psicologia da Universidade de São Paulo, São Paulo-SP.

Souza, M. P. R. (2000). A queixa escolar na formação de psicólogos: desafios e perspectivas. Em E. R. Tanamachi, M. Proença, \& M. L. Rocha. (Orgs.), Psicologia e educação: desafios teórico-práticos (pp. 105-141). São Paulo: Casa do Psicólogo.

Souza, M. P. R. (2005). Prontuários revelando os bastidores do atendimento psicológico à queixa escolar. Estilos da Clínica. 10(18), 87-107.

Tada, I. N. C., Sapia, I. P., \& Lima, V. A. A. (2010). Psicologia escolar em Rondônia: formação e práticas. Psicologia Escolar e Educacional, 14( 2), 333-340.

Tanamachi, E. R. \& Meira, M. E. M. (2003). A atuação do psicólogo como expressão do pensamento crítico em psicologia e educação. Em M. E. M. Meira \& M. A. M. Antunes (Orgs.), Psicologia escolar: práticas críticas (pp.11-62). São Paulo: Casa do Psicólogo.

Zibetti, M. L. T., Souza, F. L. F. \& Queiróz, K. J. M. (2010). Quando a escola recorre à psicologia: mecanismos de produção, encaminhamento e atendimento à queixa na alfabetização. Estudos e Pesquisas em Psicologia, 10(2), 490-506.

Recebido em: 23/03/2016

Aprovado em: 01/11/2016

\section{Sobre as autoras}

Vanessa Milani Labadessa (vanessa_milani@hotmail.com)

Psicóloga. Mestre em Psicologia (Mestrado Acadêmico em Psicologia da Universidade Federal de Rondônia / UNIR 2011). Docente do Instituto Federal de Educação Ciência e Tecnologia de Rondônia - IFRO em Ariquemes (RO).

Vanessa Aparecida Alves de Lima (limavanessa@uol.com.br)

Psicóloga. Doutora e Mestre em Psicologia Escolar e do Desenvolvimento Humano (Instituto de Psicologia da Universidade de São Paulo/USP 2000-2005). Docente da Universidade Federal de Rondônia, atualmente à disposição da Universidade Federal de Santa Catarina, Joinville. 